\title{
Gold Cluster Compounds
}

\author{
ARE THEY METALS IN MINIATURE?
}

\author{
D. Michael P. Mingos \\ Inorganic Chemistry Laboratory, University of Oxford, Oxford, United Kingdom
}

\begin{abstract}
The field of metal chuster compounds bas been studied with increasing interest in the past few years. Recent developments in the chemistry of molecular cluster compounds of gold are reviewed and the common structural types discussed. A comparison of the properties of these compounds with those of crystallites of gold and the bulk metal has been made. In addition potential applications of the molecular cluster compounds are described.
\end{abstract}

Since the mid-nineteen sixties there has been an enormous growth of interest in those compounds having metal-metal bonds and especially those with a sufficient number of metal atoms to define a three-dimensional polyhedral entity. Cotton was the first to suggest that such compounds may constitute an important general class of inorganic material and in 1964 suggested the term cluster to describe them (1). His foresight was justified by the subsequent isolation of hundreds of compounds of this type for the majority of the representative and transition elements. The major classes of cluster compounds which have been discovered are summarized in Table I together with some illustrative examples (2). Those metal clusters which might be expected to approximate most closely to the description 'metals in miniature' are those which are generated by condensation of metal atoms, for example by vaporising metals and then condensing the metal atoms by expanding the vapours rapidly through a nozzle. The nuclearities of these clusters in the gas phase can be assessed by mass spectrometry but their structural characterization cannot be based on single crystal X-ray diffraction techniques and must be inferred from circumstantial evidence based on infrared, Raman, electron and electron paramagnetic resonance spectroscopy. In addition, since these small clusters have a great tendency to aggregate to form domains of the bulk metal, their study in the condensed phase requires them to be isolated at low temperatures in a matrix.

Somewhat larger transition metal clusters of diameter 1 to $5 \mathrm{~nm}$ have been prepared on metal oxide supports and have attracted a great deal of interest because of their fundamental importance in a wide range of catalytic processes. The reactions of such clusters with petroleum feedstocks such as carbon monoxide, hydrogen and unsaturated organic molecules have been widely studied, but it has proved difficult using the currently available spectroscopic techniques to examine in detail their structures. The rational development of catalysts based on these clusters, which would possess the desired activity and selectivity characteristics, requires an understanding of the relationship between their structures and chemical reactivities. In order to provide circumstantial evidence for such structure-activity relationships, a great effort has been made towards the structural characterization of the molecular clusters illustrated in Table 1.

The closest relatives to the metal clusters described above are the 'naked' cluster cations and anions of the post-transition metals. Examples of such cluster species include $\mathrm{Bi}_{5}{ }^{3+}, \mathrm{Sn}_{5}{ }^{2-}, \mathrm{Pb}_{5}{ }^{2-}, \mathrm{Sb}_{7}{ }^{3-}$, $\mathrm{Bi}_{9}{ }^{3+}, \mathrm{Sn}_{9}^{4-}$ and $\mathrm{Ge}_{9}{ }^{2-}$ (3). Although such compounds have been structurally characterized in the solid state, their low solubilities have precluded a detailed study of their chemistries in solution. In addition, the low reactivities of the post-transition metals towards carbon monoxide, hydrogen and olefins suggest that such clusters would not mimic the high catalytic activities of the metal clusters, although they could perhaps find other applications, for example, in electron transfer processes.

Although 'bare' clusters of gold atoms have not been isolated, the alloy $\mathrm{Rb}_{4} \mathrm{Au}_{7} \mathrm{Sn}$ has $\mathrm{Au}_{7}$ clusters in the form of two tetrahedra joined by a common vertex and which are linked through $\mathrm{Sn}_{2}$ units. The gold-gold bond lengths in the cluster fragment lie in the range 275.7-278.0 $\mathrm{pm}(4)$.

The most extensively studied group of molecular clusters are

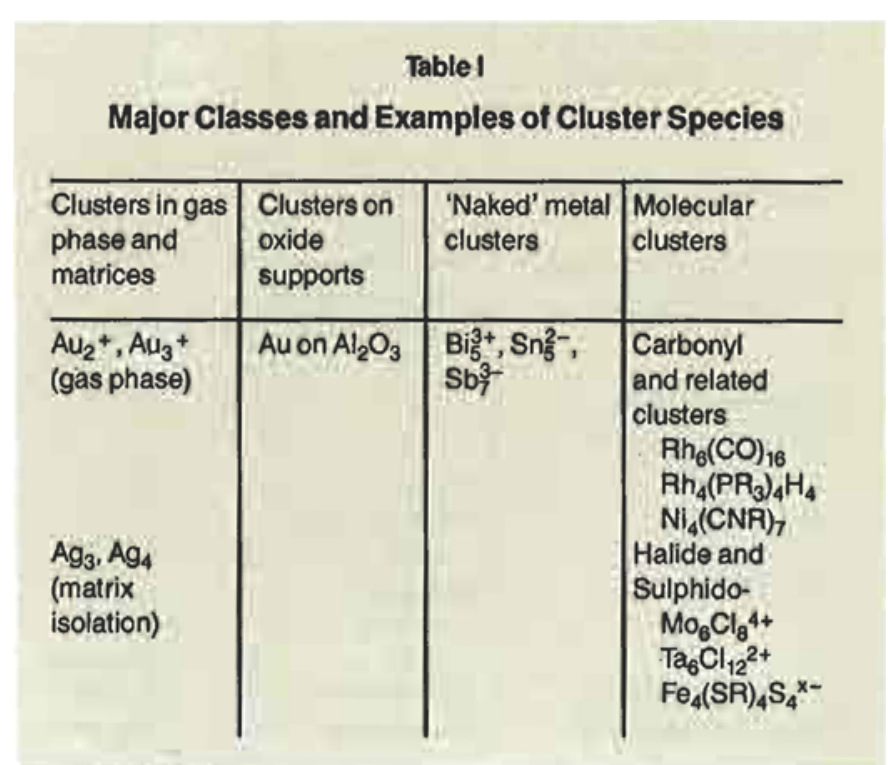


those which have the central metal polyhedron stabilised by ligands coordinated to the metal atoms. This ligand envelope not only prevents rapid aggregation of the cluster to the bulk metal, but also renders this class of molecule soluble in organic solvents and therefore amenable to detailed spectroscopic investigation. Indeed, some of these molecules are sufficiently volatile and thermally robust for mass spectrometric and U.V. photoelectron studies to be made in the gas phase. The development of high nuclearity metal carbonyl cluster compounds was pioneered by the late Paolo Chini of the University of Milan, who demonstrated that it was possible to develop effective synthetic routes to compounds of the platinum metals with up to 38 metal atoms (5). Such clusters have also been

Table II

Summary of Known Gold Cluster Cations

\begin{tabular}{|c|c|c|c|}
\hline Stoichiometry & $\begin{array}{l}\text { Polyhedral } \\
\text { geometry }\end{array}$ & $\begin{array}{l}\text { Number } \\
\text { of } \\
\text { valence } \\
\text { electrons }\end{array}$ & $\begin{array}{l}\text { Illustra- } \\
\text { tion }\end{array}$ \\
\hline Non-centred polyhedra & & & \\
\hline $\begin{array}{l}\mathrm{Au}_{4}(\mu-\mathrm{I})_{2}\left(\mathrm{PPh}_{3}\right)_{4} \\
{\left[\mathrm{Au}_{6}\left(\mathrm{P}\left(\mathrm{p}-\mathrm{C}_{6} \mathrm{H}_{4} \mathrm{Me}\right)_{3}\right)_{6}\right]^{2+}} \\
{\left[\mathrm{Au}_{7}\left(\mathrm{PPh}_{3}\right)_{7}\right]^{+}}\end{array}$ & $\begin{array}{l}\text { tetrahedral } \\
\text { octahedral } \\
\text { pentagonal bi- } \\
\quad \text { pyramid }\end{array}$ & $\begin{array}{l}54 \\
76 \\
88\end{array}$ & $\begin{array}{l}1 d \\
\text { if }\end{array}$ \\
\hline $\begin{array}{l}\text { Condensed non-centred } \\
\text { polyhedra }\end{array}$ & & & \\
\hline$\left[\mathrm{Au}_{6}\left(\mathrm{PPh}_{3}\right)_{6}\right]^{2+}$ & $\begin{array}{l}\text { edge-sharing } \\
\text { bi-tetrahedral }\end{array}$ & 76 & $2 a$ \\
\hline $\begin{array}{l}{\left[\mathrm{Au} \mathrm{u}_{6}(\mathrm{dppp})_{4}\right]^{2+}} \\
\text { Toroidal centred clusters } \\
(12 n+16 \text { electrons })\end{array}$ & $\begin{array}{c}\text { di-edge-bridged } \\
\text { tetrahedral }\end{array}$ & 80 & $1 e$ \\
\hline$\left[\mathrm{Au}_{8}\left(\mathrm{PPh}_{3}\right)_{7}\right]^{2+}$ & $\begin{array}{l}\text { icosahedron - } \\
5 \text { vertices }\end{array}$ & 100 & $4 c$ \\
\hline$\left[\mathrm{Au}_{9}\left(\mathrm{P}\left(\mathrm{p}-\mathrm{C}_{6} \mathrm{H}_{4} \mathrm{Me}\right)_{3}\right)_{8}\right]^{3+}$ & $\begin{array}{l}\text { icosahedron - } \\
4 \text { vertices }\end{array}$ & 112 & $4 d$ \\
\hline $\begin{array}{l}\left.\left[\mathrm{Au}_{9}\left(\mathrm{P}\left(p-\mathrm{C}_{6} \mathrm{H}_{4} \mathrm{OMe}\right)_{3}\right)_{8}\right)\right]^{3+} \\
{\left[\mathrm{Au}_{10} \mathrm{Cl}_{3}\left(\mathrm{PC} \mathrm{P}_{2} \mathrm{Ph}\right)_{6}\right]^{+}}\end{array}$ & $\begin{array}{l}\text { centred crown } \\
\text { tri-edge bridged } \\
\text { centred chair }\end{array}$ & $\begin{array}{l}112 \\
124\end{array}$ & $\begin{array}{l}4 b \\
4 e\end{array}$ \\
\hline $\begin{array}{l}\text { Spherical centred } \\
\text { clusters }(12 n+18 \\
\text { electrons) }\end{array}$ & & & \\
\hline$\left[\mathrm{Au}_{8}\left(\mathrm{PPh}_{3}\right)_{8}\right]^{2+}$ & $\begin{array}{l}\text { capped centred } \\
\text { chair }\end{array}$ & 102 & $1 a, 3 a$ \\
\hline $\begin{array}{l}{\left[\mathrm{Au}_{11} \mathrm{I}_{3}\left(\mathrm{P}\left(\mathrm{p}-\mathrm{C}_{6} \mathrm{H}_{4} \mathrm{~F}\right)_{3}\right)_{7}\right]} \\
{\left[\mathrm{Au}_{13} \mathrm{Cl} \mathrm{l}_{2}\left(\mathrm{PM} \mathrm{P}_{2} \mathrm{Ph}\right)_{10}\right]^{3+}}\end{array}$ & $\begin{array}{l}\text { bicapped } \\
\text { centred } \\
\text { chair } \\
\text { dodecahedron } \\
\text { icosahedron }\end{array}$ & $\begin{array}{l}114 \\
128 \\
152\end{array}$ & \begin{tabular}{|l} 
(see \\
Scheme) \\
$1 b, 3 b$ \\
$1 c, 3 c$
\end{tabular} \\
\hline
\end{tabular}

found with other ligands such as hydride, olefins, alkynes, isocyanides and phosphines. Research in this area was greatly stimulated by a report from Union Carbide Laboratories that rhodium carbonyl clusters may be acting as catalysts in the conversion of carbon monoxide and hydrogen in to ethylene glycol. This process did not reach commercial fruition because of the extreme conditions required for reasonable conversion rates (that is 1000 to $2000 \mathrm{~atm}$. and 200 to $240^{\circ} \mathrm{C}$ ).

The earlier transition metals form an extensive class of cluster compounds with halide and sulphido- ligands (6). This type of cluster has proved relevant to an understanding of metalloproteins containing, for example, $\mathrm{Fe}_{4} \mathrm{~S}_{4}$ units and enzymes such as nitrogenase which are thought to contain $\mathrm{Mo}_{x} \mathrm{Fe}_{y} \mathrm{~S}_{z}$ units. Also, reports that the Chevrel phases, a series of compounds with a remarkable resistance to quenching by magnetic fields having the general formula $\mathrm{MMo}_{6} \mathrm{~S}_{8}(\mathrm{M}=\mathrm{Pd}, \mathrm{Sn}, \mathrm{Ba}, \mathrm{Cu}, \mathrm{Au}$ or $\mathrm{Li})$, and containing a three-dimensional infinite array of linked octahedral $\mathrm{Mo}_{6} \mathrm{~S}_{8}$ cluster units, are superconducting at low temperatures have alerted the chemical community to possible relationships between cluster and solid state chemistry.

The first example of a gold cluster compound, $\mathrm{Au}_{11} \mathrm{I}_{3}\left(\mathrm{PPh}_{3}\right)_{7}$, was synthesized in the laboratories of Malatesta in Milan (7) in 1968, and subsequent developments in this rapidly expanding field have originated from research laboratories at the Universities of Nijmegen and Oxford (8). All the known cluster entities are stabilized by tertiary phosphine, $\mathrm{PR}_{3}$ and halide ligands $\mathrm{X}$. The lower nuclearity clusters have the stoichiometries $\left[\mathrm{Au}_{\mathrm{x}}\left(\mathrm{PR}_{3}\right)_{\mathrm{x}+y}\right]^{\mathrm{n}+}$ $(y=0,2)$ and the higher nuclearity derivatives $\left[\mathrm{Au}_{\mathrm{x}+1}\left(\mathrm{PR}_{3}\right)_{\mathrm{x}-\mathrm{y}} \mathrm{X}_{\mathrm{y}}\right]^{\mathrm{n}+}$. This difference arises because the higher nuclearity clusters contain an additional metal atom at the centre of the polyhedron. Figure 1 illustrates this basic stoichiometric difference and Table II summarizes the major classes of gold cluster compound which have been discovered. The fundamental purpose of this review is to examine critically the relationships between the properties of such materials and those of the bulk metal, but it is considered necessary to introduce first some of the general physical and chemical characteristics of these cluster compounds.

\section{Synthesis and Interconversion}

In general gold cluster compounds have been synthesized by the reduction of mononuclear gold phosphine complexes, $\mathrm{AuX}\left(\mathrm{PR}_{3}\right)$ ( $\mathrm{X}=$ halide, $\mathrm{NO}_{3}$ - etc.). The most commonly used reducing agent has been sodium borohydride (7), although more recently the sandwich compound Ti $\left(\eta-\mathrm{C}_{6} \mathrm{H}_{5} \mathrm{CH}_{3}\right)_{2}$ has also been used (9). These reactions can proceed with yields up to 85 per cent and some typical examples are given below (with yields in parentheses).

$$
\begin{aligned}
& \mathrm{AuI}\left(\mathrm{PPh}_{3}\right)+\mathrm{NaBH}_{4} \longrightarrow \mathrm{Au}_{11} \mathrm{I}_{3}\left(\mathrm{PPh}_{3}\right)_{7} \\
& \mathrm{AuCl}\left(\mathrm{PPh}_{3}\right)+\mathrm{Ti}\left(\eta-\mathrm{C}_{6} \mathrm{H}_{5} \mathrm{CH}_{3}\right)_{2} \longrightarrow\left[\mathrm{Au}_{2}\left(\mathrm{PPh}_{3}\right)_{8}\right]^{3+} \\
& \mathrm{AuCl}\left(\mathrm{PCyPh}_{2}\right)+\mathrm{NaBH}_{4} \longrightarrow\left[\mathrm{Au}_{6}\left(\mathrm{PCyPh}_{2}\right)_{6}\right]^{2+}
\end{aligned}
$$


Fig. 1 Some examples of centred and noncentreed gold cluster cations
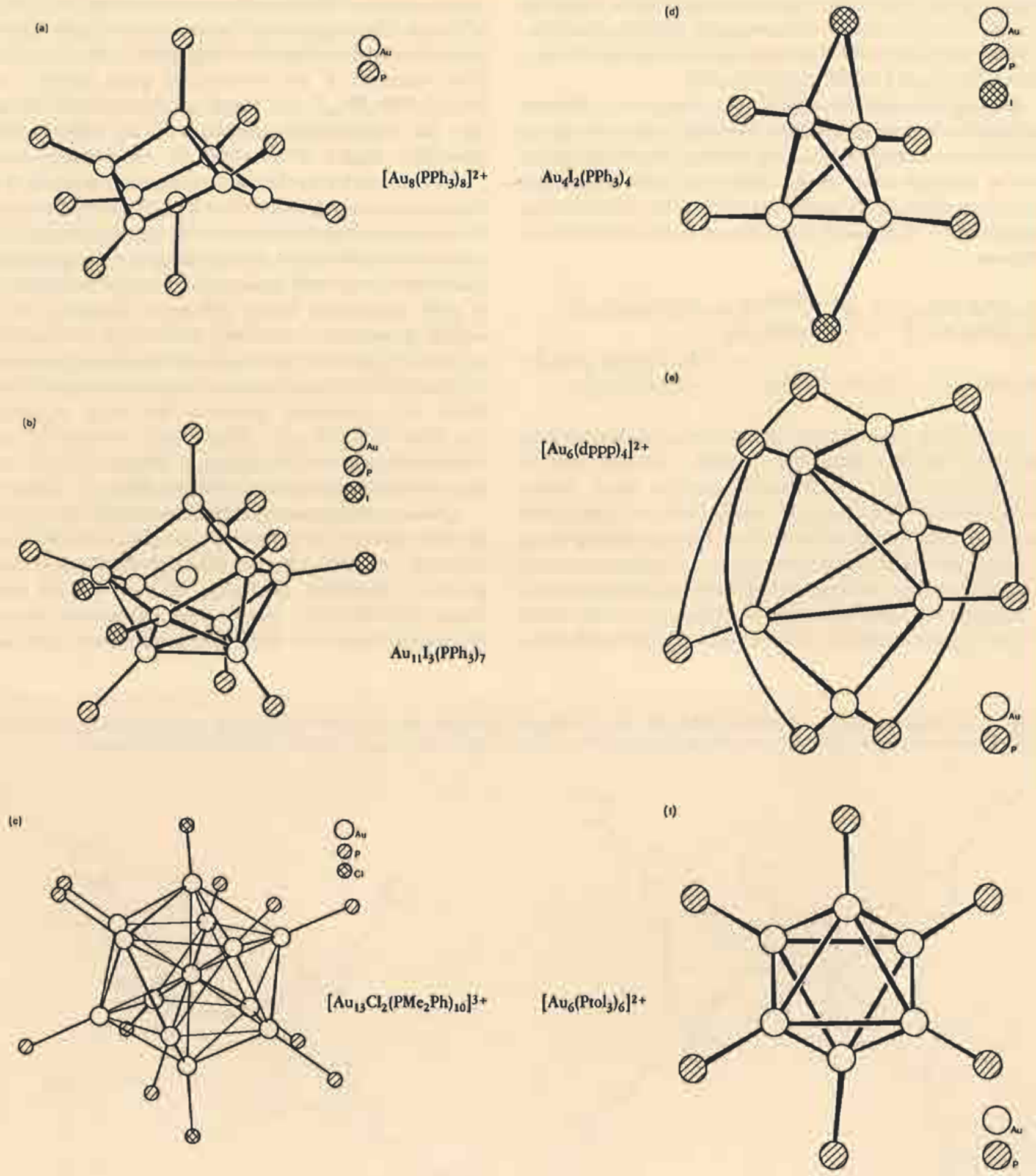
An attractive but not widely used synthetic route into gold cluster compounds is derived from metal vapour synthesis technology and involves the evaporation of gold metal atoms into a cooled $\left(-100^{\circ} \mathrm{C}\right)$ ethanolic film containing $\mathrm{AuX}\left(\mathrm{PAr}_{3}\right)$ and $\mathrm{PAr}_{3}$. Yields in the range 60 to 80 per cent have been reported for $A u_{11}$ $(\mathrm{SCN})_{3}\left(\mathrm{PAr}_{3}\right)_{7}$ and $\left[\mathrm{Au}_{9}\left(\mathrm{PAr}_{3}\right)_{8}\right]\left(\mathrm{NO}_{3}\right)_{3}(10)$.

Although the synthesis of gold cluster compounds is far from predictable it has proved possible to establish the kind of reagents which lead to cluster growth and degradation. Cluster aggregation may be achieved either by the addition of labile monomeric gold (I) complexes or by the addition of $\mathrm{Cl}^{-}$or $\mathrm{Br}^{-}$. The following examples serve to illustrate the utility of these interconversion processes.

$$
\begin{aligned}
& {\left[\mathrm{Au}_{11}\left(\mathrm{PMe}_{2} \mathrm{Ph}\right)_{10}\right]^{3+}+2 \mathrm{Cl}-\mathrm{EtOH}} \\
& {\left[\mathrm{Au}_{11}\left(\mathrm{PMe}_{2} \mathrm{Ph}\right)_{10}\right]^{3+}+2 \mathrm{AuCl}\left(\mathrm{PMe}_{2} \mathrm{Ph}\right)} \\
& \\
& \left.\left.\left[\mathrm{Au}_{8}\left(\mathrm{PPh}_{3}\right)_{8}\right]^{2+}+\mathrm{Au}\left(\mathrm{NO}_{2}\right)\left(\mathrm{PMe}_{2}\right) \stackrel{\mathrm{Ph}}{\longrightarrow} \longrightarrow\left[\mathrm{Pu}_{10}\right)_{10}\right]^{3+} \mathrm{Cl}_{2}\left(\mathrm{PMe}_{2} \mathrm{Ph}\right)_{10}\right]^{3+} \\
& {\left[\mathrm{Au}_{9}\left(\mathrm{PPh}_{3}\right)_{8}\right]^{3+}}
\end{aligned}
$$

A remarkable aspect of these reactions is their amazing facility. The above reactions which must require a complex series of fragmentation and recombination reactions occur almost instantaneously. This behaviour contrasts with the aggregation reactions of main group polyhedral molecules containing boron and carbon where the activation energies for such reactions are much larger, and catalysts are required to affect skeletal rearrangements.

It appears that in the gold phosphine cluster cations the extent of cluster growth is primarily limited by the steric demands of the peripheral ligands. When small ions such as $\mathrm{Cl}^{-}$or $\mathrm{Br}^{-}$replace one of the bulkier phosphine ligands then cluster growth can proceed until it is limited once more by the steric demands of the new set of ligands. The recognition of the importance of such steric effects was an important and significant ingredient in the synthesis of the first example of an icosahedral gold cluster cation: $\left[\mathrm{Au}_{13} \mathrm{Cl}_{2}\left(\mathrm{PMe}_{2} \mathrm{Ph}\right)_{10}\right]^{3+}$ (9). Simple calculations had demonstrated that the corresponding complex with the bulkier triphenyl phosphine ligand, $\mathrm{PPh}_{3}$, would be too sterically crowded.

For lower nuclearity clusters the competing demands of adopting a compact arrangement of metal atoms and a minimization of the non-bonded repulsions between the ligand atomscan be resolved in an alternative fashion, that is a change in cluster geometry. This possibility is particularly important in the case of molecular clusters of gold, because the energy differences separating alternative skeletal geometries are invariably rather small. For example, the summary of gold cluster geometries in Table II demonstrates three alternative skeletal geometries for the hexanuclear gold cluster cations. An octahedral geometry has been reported for $\left[\mathrm{Au}_{6}\left(\mathrm{P}\left(p-\mathrm{C}_{6} \mathrm{H}_{4} \mathrm{CH}_{3}\right)_{3}\right)_{6}\right]^{2+}$ (Figure 1(f)), and bi-edge bridged tetrahedral geometry $\left[\mathrm{Au}_{6}(\mathrm{dppp})_{4}\right]^{2+}($ Figure $1(\mathrm{e}))$ and an edgeshared bi-tetrahedral geometry for $\left[\mathrm{Au}_{6}\left(\mathrm{PPh}_{3}\right)_{6}\right]^{2+}$ (Figure 2(a)).

Cluster rearrangements can also be induced by the coordination of additional atoms or molecules to the gold cluster. For example, although $\left[\mathrm{Au}_{6}\left(\mathrm{PPh}_{3}\right)_{6}\right]^{2+}$ has the edge-sharing bi-tetrahedral geometry illustrated in Figure 2(a) the related complex $\mathrm{Au}_{6}(\mu-\mathrm{O})_{2}\left(\mathrm{PPhCy}_{2}\right)_{6}{ }^{2+}$ has the much less compact structure illustrated in Figure 2(b). The 'chair' like geometry of the latter is

Fig. 2 A comparison of the structures of $\left[\mathrm{Au}_{6}\left(\mathrm{PPh}_{3}\right)_{6}\right]^{2+}$, which has the edge-sharing bi-tetrahedral structure illustrated in (a) and $\left[\mathrm{Au}_{6}(\mu-\mathrm{O})_{2}\left(\mathrm{PCy}{ }_{2} \mathrm{Ph}\right)_{6}\right]^{2+}$ $(\mathrm{Cy}=$ cyclohexyl), which has the more open chair structure $(\mathrm{b})$. The bonds to the triply bridged oxygen atoms are indicated by the broken lines

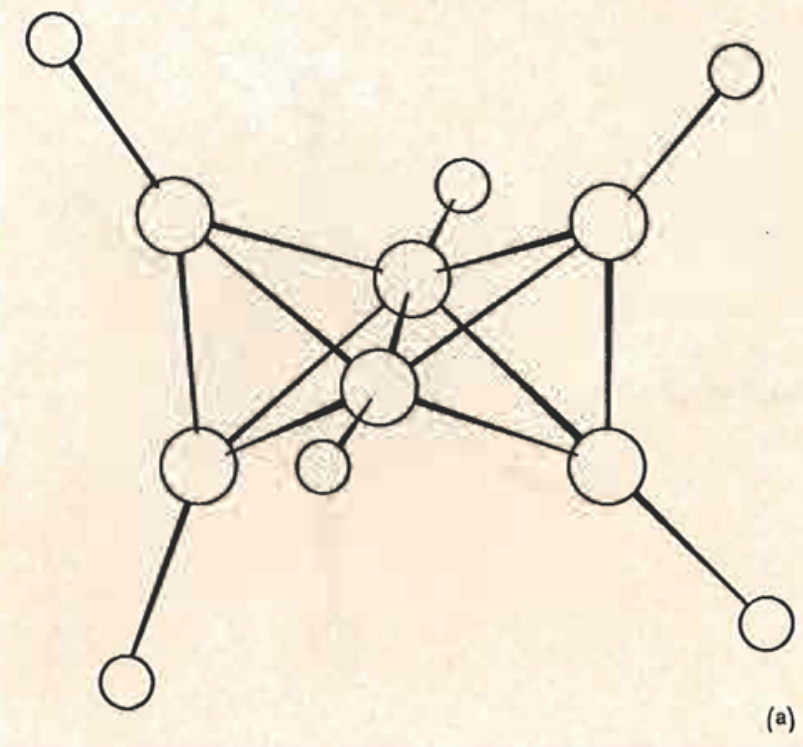

(b)

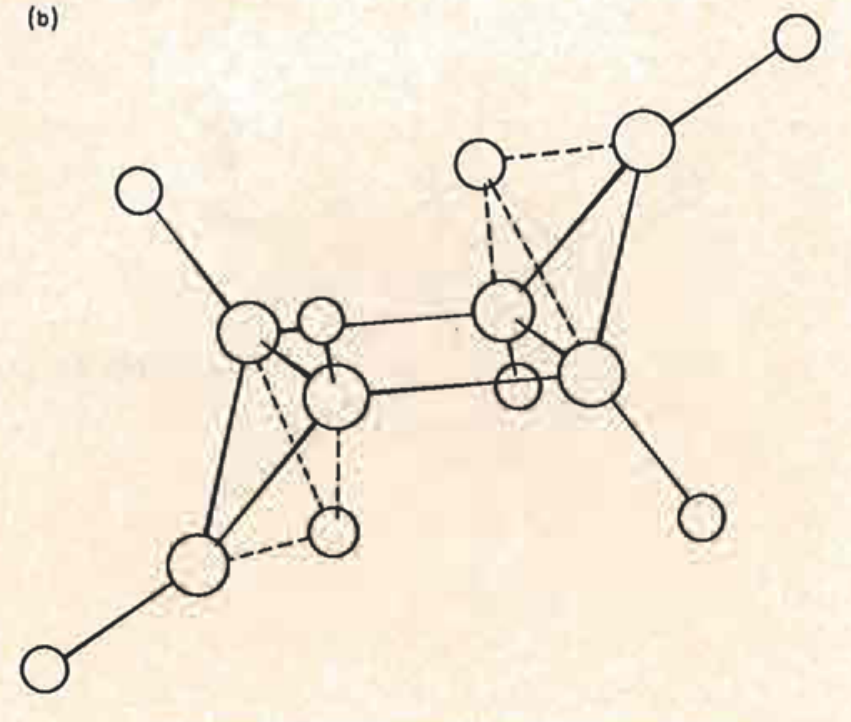


formed by the condensation of two triangular $\mathrm{Au}_{3} \mathrm{OP}_{3}+$ units, which have the oxo-ligand capping the three gold atoms. Each of the oxo-ligands can be viewed as four electron donors and the change in skeletal geometry illustrated in Figure 3 and the associated lengthening of the $\mathrm{Au}-\mathrm{Au}$ bonds can be attributed to the additional donation of electron density from the bridging oxygen atoms (12). In formal terms the oxidation states of the gold atoms have been increased from $+1 / 3$ to $+1 / 2$ by the addition of the oxo-ligands.

The compounds illustrated in Figure 2(a) and 2(b) usefully serve as structural models for following the effect of dissociative chemisorption on a small molecular cluster since their stoichiometries differ only by the addition of an $\mathrm{O}_{2}$ moiety. The dramatic change in skeletal geometry which accompanies the addition of two atoms of oxygen suggests that even for larger cluster crystallites chemisorption of oxygen and related small molecules may result in reconstruction of the cluster geometry.

\section{Structure and Bonding}

The bonding in gold cluster compounds originates primarily from the overlap of $6 s$ orbitals and is of a multicentre nature. Therefore, this type of interaction is maximized when the number of nearest neighbour gold atoms is largest and is achieved for deltahedral clusters, that is those which have triangular faces exclusively (13). For low nuclearity gold cluster compounds the commonly observed geometries either conform to this generalization, for example $\mathrm{Au}_{4} \mathrm{I}_{2}\left(\mathrm{PPh}_{3}\right)_{4}$-tetrahedral; $\left[\mathrm{Au}_{6}\left\{\mathrm{P}(\mathrm{tol})_{3}\right\}_{6}\right]^{2+}$-octahedral, $\left[\mathrm{Au}_{7}\left(\mathrm{PPh}_{3}\right)_{7}\right]+$-pentagonal bipyramidal or form condensed polyhedra derived from these fundamental polyhedra, for example $\left[\mathrm{Au}_{6}\left(\mathrm{PPh}_{3}\right)_{6}\right]^{2+}$ - edge-sharing bi-tetrahedral.

The higher nuclearity clusters are characterized by the presence of an additional central gold atom and the presence of this atom makes a fundamental contribution to the bonding because the radial metal-metal bonding to the central metal atom is stronger than the peripheral metal-metal bonding on the surface of the cluster (13). In particular, the radial gold-gold bonds in such clusters are 10 to $20 \mathrm{pm}$ shorter than the peripheral gold-gold bonds (14).

Structurally these higher nuclearity clusters fall into two categories which relate to the topology of the gold atoms on the surface of the polyhedron. Thus the compounds illustrated in Figure 3 can be described as spherical because the metal atoms lie on or close to a sphere, whereas those illustrated in Figure 4 have a more open structure whereby the peripheral atoms lie approximately on a torus, or (colloquially) resemble more closely a 'doughnut' arrangement. This topological distinction has an electronic significance since the spherical polyhedra of formula $\left[\mathrm{Au}\left(\mathrm{Au}\left(\mathrm{PR}_{3}\right)\right)_{\mathrm{n}}\right]_{\mathrm{x}}$ are characterized by a total of $12 n+18$ electrons and the toroidal polyhedra by a total of $12 n+16$ electrons (15). This close similarity in electron counts suggests that a toroidal cluster may be interconverted into a spherical cluster by electrochemical reduction. Such a geometric change, which accompanies the reduction of $\left[\mathrm{Au}_{9}\left(\mathrm{PPh}_{3}\right)_{8}\right]^{3+}$ (toroidal) to $\left[\mathrm{Au}_{9}\left(\mathrm{PPh}_{3}\right)_{8}\right]+$ (spherical) is
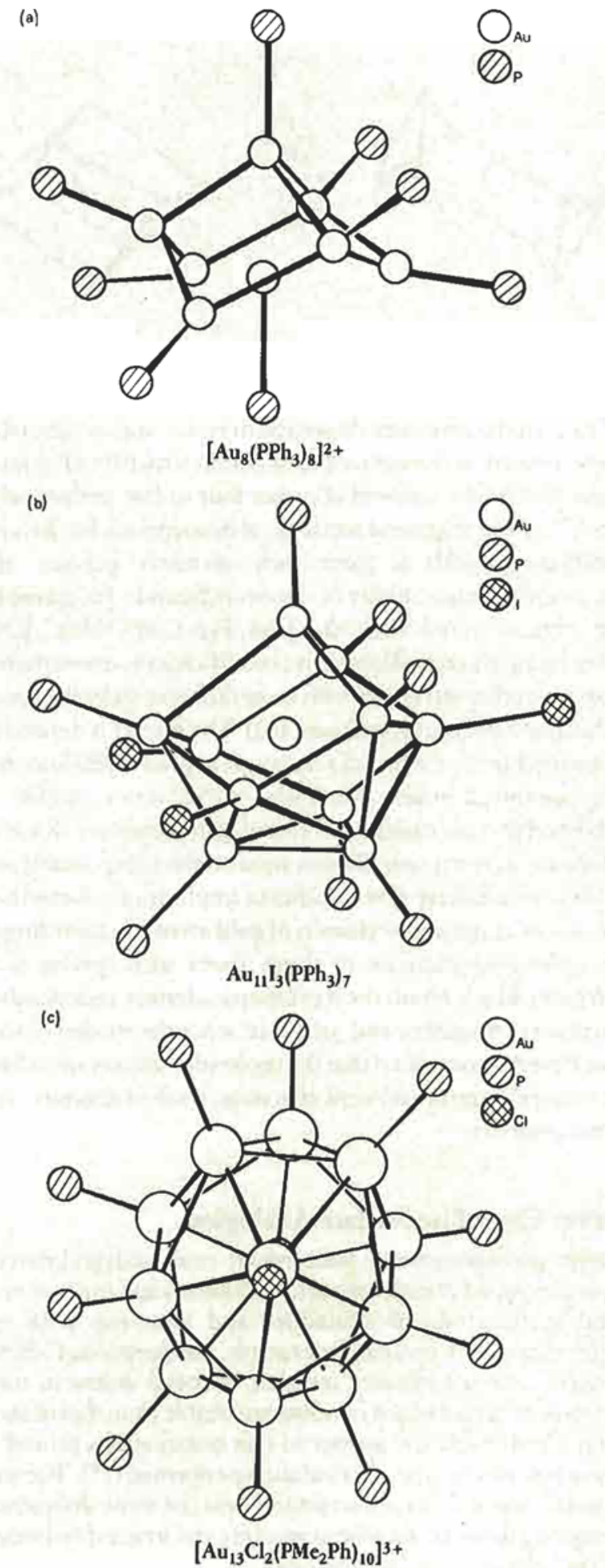

Fig. 3 Examples of centred gold cluster $\left[\mathrm{Au}\left(\mathrm{AuPR}_{3}\right)_{n}\right] \mathrm{x}+$ cations with spherical topologies and which are characterized by $12 n+18$ electrons 
illustrated below (16).

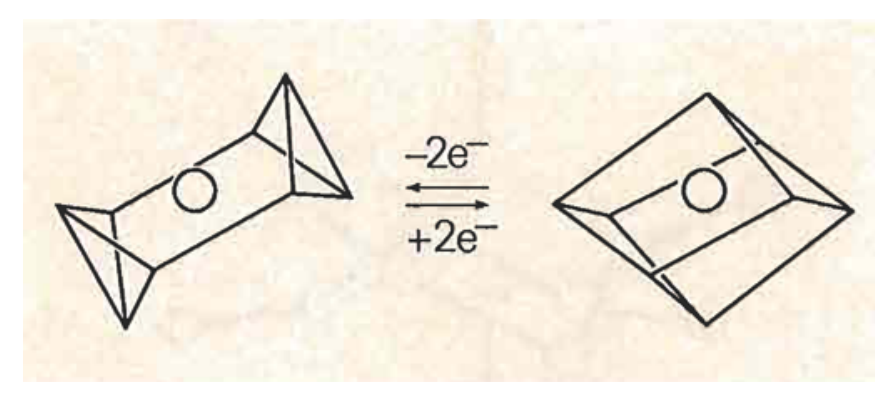

The toroidal structures illustrated in Figure 4(a), (c) and (d) may also be related to the centred icosahedral structure illustrated in Figure 3(c) by the removal of either four or five peripheral gold atoms. The use of gencral topological descriptions for this class of cluster compounds is particularly necessary because of the stereochemical non-rigidity of these compounds. For example, we have demonstrated that the $\left[\mathrm{Au}_{9}\left\{\mathrm{P}\left(p-\mathrm{C}_{6} \mathrm{H}_{4} \mathrm{OMc}\right)_{3}\right\}_{8}\right]\left(\mathrm{NO}_{3}\right)_{3}$ cluster cation co-crystallizes in two modifications, oneorthorhombic and the other tetragonal with quite different skeletal geometries as illustrated in Figures 4(b) and 4(d). The former is derived from an icosahedron by the loss of a rectangle of gold atoms and the latter is a centred crown. Similarly ${ }^{3} \mathrm{P}\{\mathrm{l} \mathrm{H}\}$ n.m.r. studies have established that the majority of centred gold phosphine cluster compounds are stereochemically non-rigid on the n.m.r. time scale (8).

These results have very significant implications about the way in which we think about clusters of gold atoms on inert supports. It is quite inappropriate to think about such species as rigid aggregates which retain their geometric identity independent of chemical environment and substrate, since the studies described above have demonstrated that the molecular clusters are so flexible that minor electronic and steric effects can result in dramatic skcletal rearrangements.

\section{Cluster-Crystallite-Surface Analogies}

It has become common to attempt to establish links between the newly developed chemistries of metal clusters and the properties of metal surfaces, metal crystallites and even the bulk metal. Theoreticians have probed, for example, the question of when does a cluster have a sufficient number of metal atoms to have an electronic structure which is indistinguishable from that of the bulk metal. Predictably the answer to this question has proved to be dependent on the type of calculation performed (17). The writer's personal view is that such analogies bear the same deficiencies as attempting to relate benzene to graphite and strained hydrocarbons such as cubane, $\mathrm{C}_{8} \mathrm{H}_{8}$, to diamond.

Clearly the basic geometric and bonding characteristics of the two materials are related, but the physical properties of the bulk material such as electrical conductivity and hardness require the presence of an infinite periodic lattice, and it is quite inappropriate to search for these properties in smaller aggregates. One anticipates a greater deal of structural flexibility for a small aggregate of atoms, and this feature may be illustrated in gold cluster chemistry by noting that although the average metal-metal bond lengths observed are close to those reported for the bulk metal (288.4 pm) the actual range of observed leng ths is large viz. 260 to $310 \mathrm{pm}$. This suggests that the potential energy surfaces for the compression and elongation of gold-gold bonds are soft.

Similarly the great diversity of structure observed for stoichiometrically related cluster compounds and their stereochemical non-rigidity in solution suggest that it is inappropriate to view gold cluster compounds as rigid chunks of the solid state bulk structure, which is face centred cubic. Indeed the cluster structures are dependent on the total electron count adopting either spherical or toroidal topological arrangements and are also sensitive to subtle electronic and steric effects in the solid state.

These results suggest that those scientists studying the catalytic properties of crystallites of gold on inert supports should recognise that the clusters may change their geometries as a result of introducing substrates and changes in environment.

Although the molecular gold cluster compounds which have been characterized to date bear little structural relationship to the bulk metal they may have some structural features common to crystallites of gold. For example, Alpress and Sanders (18) have demonstrated using electron microscopy that at high saturation levels crystallites of gold with five-fold symmetry can be distinguished. Molecular gold clusters with seven and thirteen metal atoms also adopt polyhedra with five-fold symmetry in an attempt to maximize the number of gold-gold bonding interactions (see Table II).

The molecular gold cluster compounds are not good conductors of electricity in the solid state, because the individual cation cluster ions are well separated and the phosphine ligands behave as an insulating sheath around the metal clusters.

The electronic structures of gold cluster compounds have also been probed by $\mathrm{X}$-ray photoelectron spectroscopy and the valence band ionizations for a series of clusters are illustrated in Figure 5 (19). The valence band region for the clusters has an appearance which is intermediate between that observed for mononuclear gold compounds, for example $\mathrm{AuX}\left(\mathrm{PPh}_{3}\right)$, and the bulk metal, and even for 11 gold atoms the band structures for the cluster and the metal are clearly distinguishable, suggesting that only when there are more than 20 metal atoms do the electronic structures of the clusters closely approach those of the bulk metal.

To date no reports have appeared of catalytic applications of gold cluster compounds. This is not altogether surprising in view of the relatively low activity of elemental gold in catalytic processes (20) although the metal shows some promise in selective catalysis applications (20a). In the writer's own laboratories some preliminary investigations have been made of the homogeneous catalytic activities of gold cluster compounds and it has been established that they are less active than $\mathrm{Ag}^{+}$, for example, in catalyzing skeletal rearrangements of strained hydrocarbons. 

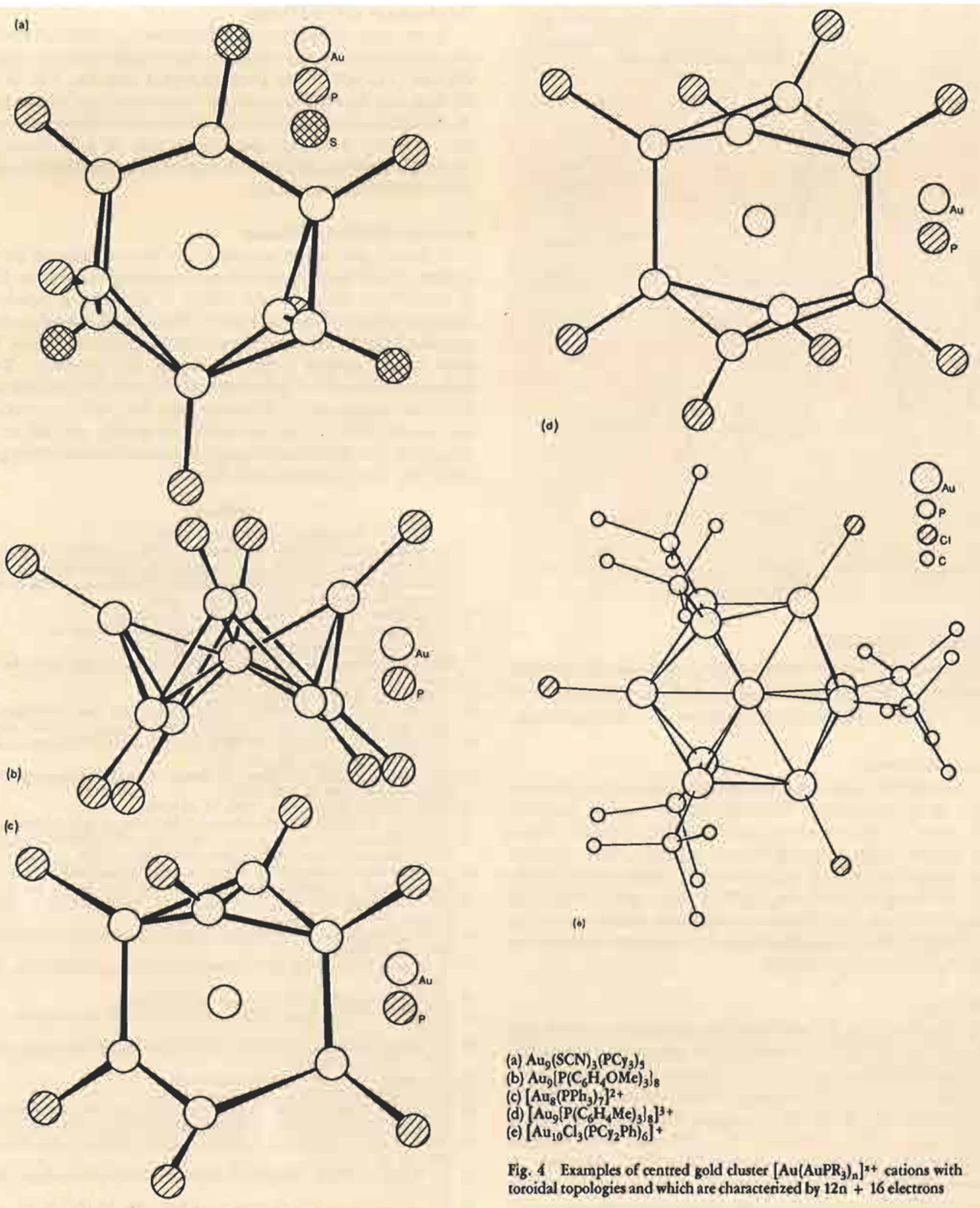

(a) $\mathrm{Au}_{9}(\mathrm{SCN})_{3}\left(\mathrm{PCy}_{3}\right)_{9}$

(b) $\mathrm{Au}_{9}\left[\mathrm{P}\left(\mathrm{C}_{6} \mathrm{H}_{4} \mathrm{OMe}\right)_{3}\right]_{8}$

(c) $\left[\mathrm{Au}_{8}\left(\mathrm{PPh}_{3}\right)_{7}\right]^{2+}$

(d) $\left[\mathrm{Au}_{9}\left[\mathrm{P}\left(\mathrm{C}_{6} \mathrm{H}_{4} \mathrm{Me}\right)_{3}\right)_{8}\right]^{3+}$

(e) $\left[\mathrm{Au}_{10} \mathrm{Cl}_{3}\left(\mathrm{PCy}_{2} \mathrm{Ph}\right)_{6}\right]^{+}$

Fig. 4 Examples of centred gold cluster $\left[\mathrm{Au}\left(\mathrm{AuPR}_{3}\right)_{n}\right]^{x+}$ cations with toroidal topologies and which are characterized by $12 n+16$ electrons 


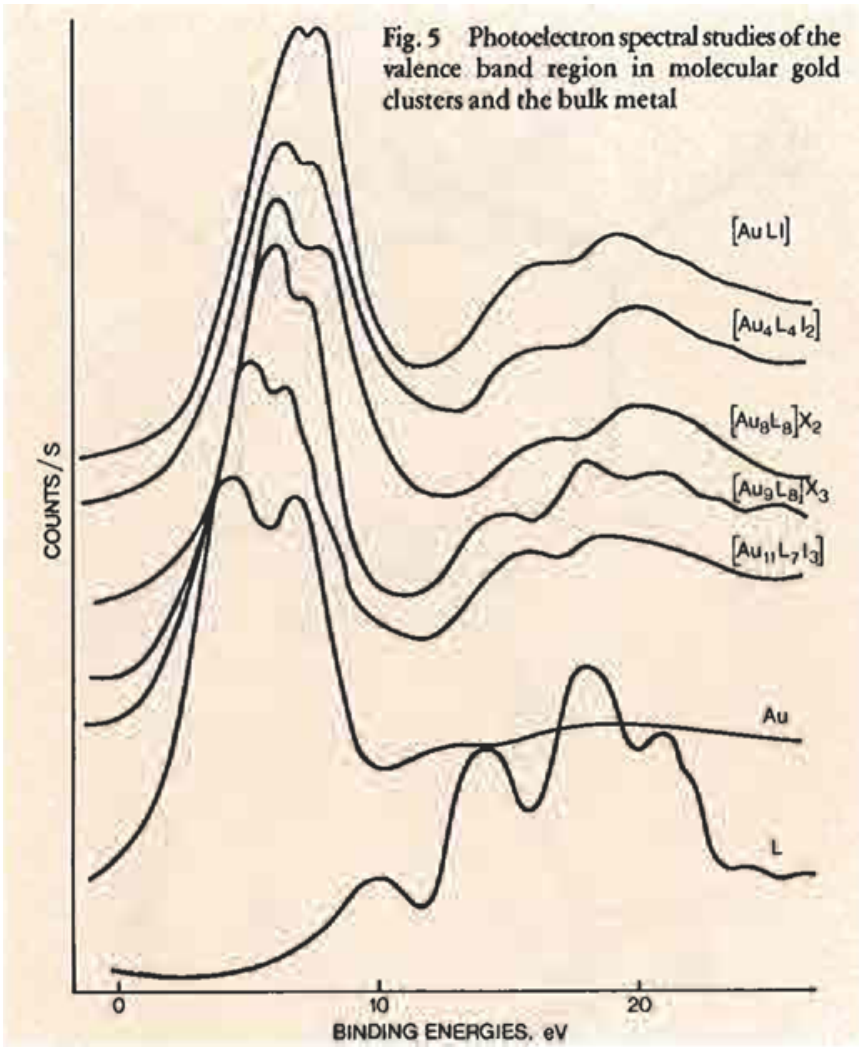

\section{Potential Applications}

Although the molecular cluster compounds of gold may have only limited applications in the arca of catalysis, attention can be drawn to other areas where these compounds have shown promise.

\section{Electron Microscopy}

In biology there are many interesting structural problems for which an electron-dense labelling reagent with a potential resolution of $5.0 \mathrm{~nm}$ or less would be very useful. Gold colloids have been studied in this respect for several years (21), but it was only recently that Bartlett et al. (22) were able to demonstrate that the water soluble gold clusters $\mathrm{Au}_{11} \mathrm{X}_{3}\left(\mathrm{PAr}_{3}\right)_{7}\left(\mathrm{Ar}=p-\mathrm{C}_{6} \mathrm{H}_{4} \mathrm{NH}_{2}\right)$ had the correct characteristics for such applications. Subsequently this type of reagent has been used successfully in an electron microscopy study of the protein avidin (23).

\section{Gold Plating}

The gold compounds used for decorating china and articles and known as 'liquid golds' are made by the interaction of gold (III) complexes with sulphurized terpenes or resins and are very soluble in organic solvents, and presumably contain clusters or aggregates of gold atoms. A recent patent has suggested that the incompletely characterized cluster compound $\mathrm{Au}_{55}\left(\mathrm{PPh}_{3}\right)_{12} \mathrm{X}_{6}$ may be used effectively for gold plating applications (24). However, a comparative study of the sulphur and phosphine gold complexes as plating solution components has not been reported to date.

\section{Development of Gold Drugs}

A new range of drugs based on linear gold(I) triethylphosphine complexes has been developed for the treatment of rheumatoid arthritis (25) and it has been proposed that the role of the trie thylphosphine is to enhance the lipid solubility of the drug and thereby facilitate its absorption and distriburion in the body. Clearly the synthesis of new cluster compounds of gold based on triethylphosphine could provide an interesting possible extension of this type of chemotherapy.

\section{Extractive Metallurgy of Gold}

In recent years some processes have been developed for the recovery of gold from cyanide solutions (predominantly in the form of $\mathrm{Au}(\mathrm{CN})_{2}^{-}$) based on the ability of granular or powdered activated carbon to absorb the gold. Generally the carbon granules are added directly to pulp derived from the cyanide solutions. The gold loaded carbon is later recovered by screening. X-ray photoelectron studies of gold activated carbons by McDougall $e t a l$. (26) have suggested an oxidation state for gold intermediate between $(0)$ and $(+1)$ for the adsorbed species, and led to the suggestion that gold cluster species similar to the molecular gold phosphine clusters might be present.

\section{References}

1 F.A. Cotton, Inorg. Chem., 1964, 3, 1217-1220

2 For general reviews of metal cluster chemistry see for example: E.L. Muetterties, Chem. Eng. News, Aug. 30th, 1982, pp. 28-41; F.A. Cotton and M.H. Chisholm, Chem. Eng. News, Jun. 28th, 1982, pp. 40-54; B.F.G.Johnson, 'Transition Metal' Clusters', John Wiley and Sons, New York, 1980

3 J.D. Corbett, Accounts Cbem. Res, 1981, 14, 239-246

4 H.-D. Sinnen and H.-U. Schuster, Z. Naturforsch., 1981, 36b, 833

5 P. Chini, J. Organometal. Chem., 1980, 200, 37-61

6 R.H. Holm, Chem. Soc, Rev., 1981, 10,455; A. Simon, Angew. Chem. Int. Ed, $1981,20,1-21$

7 L, Malatesta, Gold Bull, 1975, 8, (2), 48-52

8 J.J. Steggerda, J.J. Bour and J.W.A. van der Welden, Recl. Trav. Chim. Pays-Bas., 1982, 101, 164-170; K.P. Hall and D.M.P. Mingos, Prog. Inorg. Chem., in press

9 C.E. Briant, B.R.C. Theobald, J.W. White, L.K. Bell and D.M.P. Mingos, J. Chem. Soc. Chem. Commun., 1981, 201-202

10 F.A. Vollenbroek, D.C.P. Bouten, J.M. Trooster, J.P. van der Berg and J.J. Bour, Inorg. Chem., 1980, 19, 2685-2688

11 D.M.P. Mingos, Inorg. Chem., 1982, 21, 464-466

12 C.E. Briant, K.P. Hall, A.C. Wheeler and D.M.P. Mingos, unpublished resulrs

13 D.M.P. Mingos, J. Chem. Soc. Dalion Trans., 1976, 1163-1169; D.G. Evans and D.M.P. Mingos, J. Organometal. Chem., 1982, 232, 171-191

14 For references to structural studies on gold cluster compounds sec P.G. Jones, Gold Bull., 1981, 14, (3), 102-118; 1981, 14, (4), 159-166; 1983, 16, (4), 114-124

15 K.P. Hall, B.R.C. Theobald, D.I. Gilmour, A.J. Welch and D.M.P. Mingos, J. Chem. Soc. Chem. Commun., 1982, 528-530

16 J.G.M. van der Linden, M.L.H. Paulissen and J.E.J. Schmitz,J. Amer. Chem. Soc, $1983,105,1903-1907$

17 A. Veillard, J. Demuynck, M.M. Rohmer and A. Strich, J. Chem. Pbys., 1981, 75,3443

18 J.G. Alpress and J.V. Sanders, Surf. Sci., 1967, 7, 1-25

19 G. Battisconi, G. Mattagno, L. Naldini and R. Zanoni, J. Electron Spectrosc., 1982, 28,23

20 G.C. Bond, Gold Bull., 1972, 5, (1), 11-13; G.C. Bond and D.A. Sermon, Gold Bull., 1973, 6, (4), 102.105

20aJ. Schwank, Gold Bull., 1983, 16, (4), 103-110

21 M. Horisberger, Gold Bull., 1981, 14, (3), 90-94

22 P.A. Bartlett, B. Bauer and S.J. Singer, J. Am. Chem. Soc., 1978, 100, 5085-5089

23 D. Safer, J. Hainfield, J.S. Wall and J.E. Reardon, Science, 1982, 218, 290-291

24 Wacker-Chemie, GmbH, European Pat. Appl. 66,287 (1982); Plat. Met. Rev., $1983,27,99$

25 G.J. Higby, GoldBull., 1982, 15, (4), 130-140; P.J. Sadler, Struct. Bond., 1976, 29, 171-211

26 G.T. McDougall and R.D. Hancock, Gold Bull., 1981, 14, (4), 138-153 